Open Access

\title{
The Inhibition of Superoxide Production by the Soluble Phase of Cystic Fibrosis Sputum
}

\author{
Amrita Dosanjh*
}

Department of Pediatrics, University of California School of Medicine, San Diego, CA 92122, USA

\begin{abstract}
Background: Cystic fibrosis (CF) lung disease is characterized by an infiltration of activated neutrophils. Oxidative radical formation and neutrophil proteases may interact with the components of CF airway secretions. This study examined the soluble factors in CF airway secretions (sol) and determined their effect on the production of superoxide radicals.

Methods: Neutrophils were isolated from three normal subjects. Each preparation of neutrophils can be used in several experiments on the same day of preparation. Using a standardized cytochrome c reduction method, the effect of pooled $\mathrm{CF}$ sol isolated from nine $\mathrm{CF}$ patients, on neutrophil superoxide production was studied.

Results: CF sol phase significantly attenuates the production of superoxide by phorbol stimulated control neutrophils in a time and concentration dependent manner. When CF sol is boiled, the inhibitory effect on superoxide was reversed. CF soluble heat labile factors clearly attenuated superoxide production, independent of elastase concentration. We conclude that the presence of heat labile soluble factors in CF sputum, serve to attenuate superoxide production by human neutrophils.
\end{abstract}

Keywords: Cystic fibrosis, superoxide, neutrophil, sputum.

\section{INTRODUCTION}

Cystic Fibrosis (CF) a common genetic disorder, is characterized by chronic bronchiectasis and chronic lung infections typically associated with Pseudomonas aeruginosa. The inflammatory lung disease of Cystic Fibrosis involves an accumulation of polymorphonuclear neutrophils (pmns) in the large and small airways. When activated, neutrophils infiltrate the lung and produce oxygen radicals and proteases, with superoxide as one significant product. The production of superoxide and its interaction with factors present in the CF airway may be a major determinant of lung injury in the disease. Oxygen radicals can cause cellular damage by membrane lipid peroxidation and protein sulfhydryl oxidation, leading to anti-protease inactivation and strand breaks in nucleic acids $[1,2]$. CF sputum contains high quantities of cytokines and mediators such as leukotriene LTB4 and IL-8, as well as elastase $[3,4]$. We hypothesized that soluble factors in $\mathrm{CF}$ airway secretions may alter the production of superoxide by neutrophils. This in turn may contribute to increased bacterial growth, and the associated lung injury in the disease. The aim of this study was to describe the effect of the soluble phase of CF airway secretions on the production of superoxide anion.

\section{MATERIALS AND METHODS}

\section{Human Neutrophil Isolation}

Circulating neutrophils were obtained from normal healthy volunteers $(n=3)$. Following venopuncture, blood

\footnotetext{
*Address correspondence to this author at the Department of Pediatrics, University of California School of Medicine, San Diego, CA 92122, USA; Tel: 858442 6146; E-mail: adosanjh@ucsd.edu
}

was processed by dextran sedimentation, hypotonic lysis of contaminating red cells, and fractionation over a stepgradient of Ficoll-Hypaque to remove contaminating mononuclear cells, using methods previously published $[1,5]$. Yield from this procedure was usually five to six million cells per donor with the purity of $>98 \%$. The isolated pmns were kept on ice with occasional gentle agitation to prevent aggregation. From each preparation of pmns, multiple experiments could be completed. Blood products were handled and disposed of according to guidelines by the institution.

\section{Kinetic Microplate Assay for Superoxide Production}

A very sensitive and widely established assay for monitoring superoxide generation is the cytochrome $\mathrm{c}$ reduction assay [5]. The use of this assay was the basis of superoxide determination for this study and has been previously described in detail $[5,6]$.

The temperature of the reaction wells was very well controlled to maximize superoxide production. A closed incubation chamber that maintained microplate at $37^{\circ} \mathrm{C}$ and a Vmax kinetic reader with a plexiglass incubator with a front access door were utilized. The temperature variation was only $+/-1.0 \%$ under these conditions.

Prior to beginning the assay, the 96 well microtiter plate, PBS supplemented with $0.9 \mathrm{mM} \mathrm{CaCl} 2,0.5 \mathrm{mM} \mathrm{Mg} \mathrm{Cl} 2$ and $7.5 \mathrm{mM}$ glucose (PBSG) and the $1.5 \mathrm{mM}$ cytochrome c solution were all preincubated to $37^{\circ} \mathrm{C}$. Then, just prior to the start of the assay, the following reagents were added to each well: $0.176 \mathrm{ml}$ PBSG, $0.0125 \mathrm{ml}$ cytochrome c stock, 0.005 $\mathrm{ml}$ of either superoxide dismutase stock solution $(60 \mathrm{ug} / \mathrm{ml})$ or $5 \mathrm{ul}$ of sterile water and 50ul of cell suspension. The contents were mixed and equilibrated to $37^{\circ} \mathrm{C}$ for two minutes. The microtiter plate was read at $550 \mathrm{~nm}$ in the kinetic mode 
for at least 5 minutes. When the added factors such as sol were added, they were pre-incubated with the pmns for specified time periods. Superoxide production was measured in the presence of the factor being tested.

The results were expressed by plotting the $\mathrm{mOD} / \mathrm{minute}$ change versus time. Control was set to $100 \%$ and samples with added sol were then compared to control and expressed as a percentage. The established assay was a sensitive and specific way to measure rates of PMA and FMLP induced superoxide production, as described in further detail by Mayo and Curnutte [5].

\section{Isolation of Sol and Biochemical Analysis}

Fresh sputum was collected from Cystic Fibrosis patients $(n=9)$ and kept on ice during the collection. A minimum of $10 \mathrm{ml}$ was collected in a sterile container. The sputum was then centrifuged at $90,000 \mathrm{~g}$ for 90 minutes at $4{ }^{\circ} \mathrm{C}$, to yield a clear supernatant described as sol. The sol was pooled $(n=9)$ in the experiments, to minimize the effect of any individual variability in sol composition that may exist. All patients were not acutely ill, non-hospitalized but all the CF patients did have chronic Pseudomonas aeruginosa endobronchitis. None had colonization with Burkholderia cepacia. Genotype information was not available on all patients, however all the patients shared the common classic features of moderate to severe CF lung disease.

The sol layer was saved and utilized in the cytochrome c assay. In addition, small aliquots of the pooled sol phase from several $\mathrm{CF}$ patients were also heat inactivated at $100^{\circ} \mathrm{C}$ for fifteen minutes. These aliquots were used in the assay system described and comparison was made to sol-free controls. The inhibitory effect of sol, in the presence of antitryp$\sin (0.1 \mathrm{mg} / \mathrm{ml})$ or specific blocking antibody against LTB4 or mucin component, alginate $(50 \mathrm{ug} / \mathrm{ml})$, was also studied.

\section{Statistical Analysis}

Student's t test was used. A p value of $<0.5$ was considered significant.

\section{RESULTS}

\section{CF Sol and Neutrophil Superoxide Production}

Our results show that the addition of $\mathrm{CF}$ sol phase significantly attenuates the production of superoxide by phorbol stimulated control neutrophils. This was a consistent result of several experiments, using three different preparations of control pmns and pooled sol preparations from nine CF patients. The inhibitory effect of CF sol is concentration and time dependent. The length of neutrophil pre-incubation of $9.4 \mathrm{ug} / \mathrm{ml} \mathrm{CF}$ sol protein was directly related to the extent of inhibition of neutrophil superoxide production, or its increased consumption. The thirty minute incubation lowered the $\mathrm{mOD} / \mathrm{min}$ readings by $83+/-7 \% \%$ compared to control $(100 \%+/-0)(\mathrm{p}<0.05)$. This was a consistent result of several experiments.

The decrease in superoxide dependent cytochrome c reduction was fully inhibitable by superoxide dismutase, thus verifying that this reduction reaction was due to the presence of superoxide.

Dose Dependent Inhibition of Superoxide Production by Sol

When the CF sol phase was added to the reaction mixture in concentrations ranging from 0 to $150 \mathrm{ug} / \mathrm{ml}$ of protein, while keeping PMA concentration constant, the dosedependent inhibition of superoxide production by $\mathrm{CF}$ sol is clearly demonstrated (Fig. 1, p<0.05). This was a consistent result of four separate experiments. Furthermore, this attenuation is also seen with receptor mediated agonist, FMLP. Pre-incubation of neutrophils with CF sol results in the reduction of superoxide production at all concentrations of FMLP used.

\section{Inhibition of PMN Respiratory Burst by CF sol}

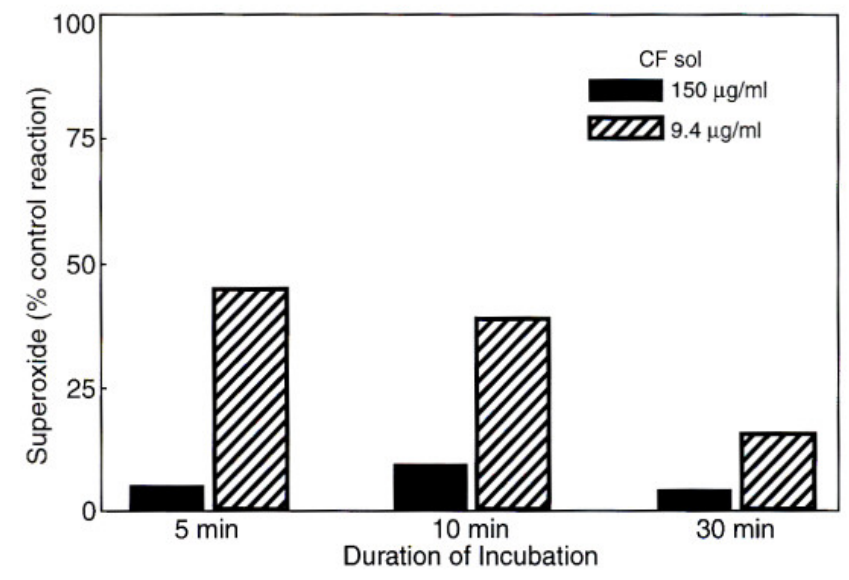

Fig. (1). The dose dependent inhibition of superoxide production by $\mathrm{CF}$ sol protein is shown, error bars indicate standard deviation from the mean, $\mathrm{p}<0.05$.

\section{Heat Inactivation, Antitrypsin and a Cellfree System}

The factors responsible for this downregulation of superoxide production appear to be unrelated to the presence of elastase in the sol. If $150 \mathrm{ug} / \mathrm{ml}$ of sol protein and $\alpha 1$ antitrypsin $(0.1 \mathrm{mg} / \mathrm{ml})$ in 100 fold excess, was added to each reaction mixture, the inhibition of superoxide production is not reversed. This would suggest that the attenuating effect of sol on free oxygen radical production is not related to the enzymatic cleavage of receptor sites by proteases such as elastase. Furthermore, characterization of the factor(s) in $\mathrm{CF}$ sol suggest that they are heat labile. When CF sol is boiled, the inhibitory effect on superoxide production is reversed (Fig. 2, p <0.05). CF sol does not appear to be cytotoxic since trypan blue exclusion was similar in control and treated pmns (data not shown). The xanthine/xanthine oxidase assay was used to generate superoxide in a cell free system. CF sol addition to this cell free assay did not change the superoxide production compared to control, thus demonstrating that sol does not act as a scavenger for superoxide $(p=n s)$. The inhibitory effect of sol, in the presence of antitrypsin $(0.1 \mathrm{mg} / \mathrm{ml})$ or specific blocking antibody against LTB4 or mucin component, alginate $(50 \mathrm{ug} / \mathrm{ml})$, was also studied, and no effect on superoxide production was noted. 


\section{Characterization of CF sol Effect}

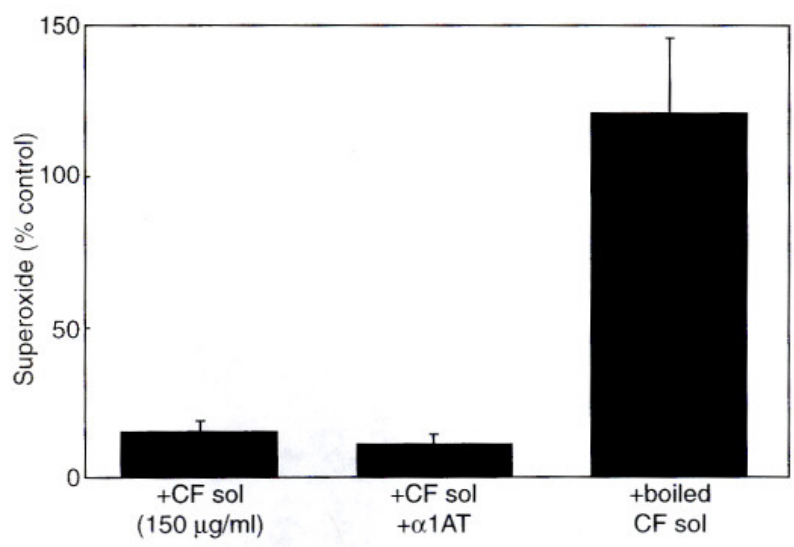

Fig. (2). The inhibitory effect of CF sol is reversed by boiling (115 $+/-40 \%$ v. $12+/-3 \%, \mathrm{p}<0.05)$. The effect of added sol is unchanged by addition of anti-protease $(\mathrm{p}=\mathrm{ns})$.

\section{DISCUSSION}

This study was conducted to describe the effect of the soluble phase of CF airway secretions on the production of superoxide radicals. Our results show that there are heat labile factor(s) in the sol phase of CF sputum which can attenuate the production of superoxide by stimulated human neutrophils. Upon further characterization, the factor appears not to be elastase, since the pre-incubation with anti-protease in excess to neutralize elastase did not reverse the sol effect. The sol does not appear to have a cytotoxic effect, and does not act as a direct scavenger of superoxide, as shown by the trypan blue and xanthine oxidase experiments performed. Preliminary characterization of possible factors indicated that alginate, a major polysaccharide component of mucin, has no effect on superoxide production in the assay system studied. The use of anti-LTB4 as a blocking antibody to potent inflammatory agent, LTB4, also had no effect. This may effect may be found in other obstructive lung diseases, such as COPD, since the role of neutrophil based lung damage. The study of COPD was beyond the scope of this study. In addition, the experiments utilitzed pmns from normal healthy controls, since the literature on this assay support this use. Further study of CF neutrophils may be warranted. It is not clear however in the literature if $\mathrm{CF}$ neutrophils are defective.

The genetic defect identified in CF leads to hypersecretion of thick mucus by the mucus glands and submucosal glands in the upper and lower airways which can lead to obstructive lung disease. CF sputum has been shown to have chemotactic activity for neutrophils [7-10]. Kharazmi et al. have shown that CF sputum, particularly the sol phase, can prime healthy neutrophils to generate a three to five fold increase in chemiluminescence in response to FMLP [11]. It was suggested that since priming activity was resistant to heating the sol phase to $100^{\circ} \mathrm{C}$ for fifteen minutes, the effect on the respiratory burst was due to immune complexes and endotoxins.

The Cystic Fibrosis Transmembrane Conductance regulator protein (CFTR) a cAMP dependent channel, is the gene product identified in the disease [12]. CFTR may play a role in the regulation of superoxide production. CFTR is expressed in neutrophils and mutant CFTR may alter normal pmn functioning. The activation of chloride channels may influence production of oxygen radicals in stimulated pmns. Since the major defect known in Cystic Fibrosis is diminished chloride conductance through the CFTR channel, it is possible that previous reports of altered superoxide production in CF neutrophils which express a mutant CFTR protein may be related to altered chloride flux [13].

The studies of other groups measuring reactive oxygen radicals by the luminol method were completed prior to the identification of the $\mathrm{CF}$ gene. The CFTR protein which is defective in $\mathrm{CF}$ is a cAMP dependent chloride channel. Reports have suggested many other roles for CFTR including the regulation of endocytic trafficking, organelle acidification and an alteration of glycosylation of secreted products, such as mucin [14-16]. Its possible role in oxygen radical formation has yet to be studied. The host-defense mechanisms of Cystic Fibrosis patients may be impaired and contribute to the acute and progressive lung injury associated with the disease [17]. Oxygen radicals are potent defenses against bacterial infection, but can simultanously cause cross-linking of membrane and intracellular proteins, peroxidative changes in membrane lipids and DNA damage. In $\mathrm{CF}$ patients oxygen free radical generation from activated neutrophils can contribute to chronic lung inflammation. Pancreatic insufficiency in these patients leads to severe deficiencies in fat-soluble antioxidants, such as vitamin $\mathrm{E}$ and carotenoids, resulting in impaired antioxidant production. The overproduction of superoxide and the underrepresentation of antioxidants results in an imbalance favoring oxidant mediated lung injury [18]. The chronic presence of Pseudomonas aeruginosa in the airway results in reactive oxygen species and proteolytic enzyme release [19]. The $\alpha 1$ - antiprotease $(\alpha 1-\mathrm{PI})$ levels in $\mathrm{CF}$ patients and controls are similar [20], however the large increase in pmn elastase in the respiratory tract of these patients may negate the neutralization capacity of this proteinase inhibitor. There is also evidence that $95 \%$ of neutrophil elastase in $\mathrm{CF}$ bronchoalveolar lavage fluid is not complexed to $\alpha 1-\mathrm{PI}$. The formation of the complex may be defective and due to inactivation of lipid peroxidation $[21,22]$. A recent study has shown that neutrophils derived from CF patients generate higher levels of superoxide anion than controls [23]. This finding highlights further the possible importance of the sol and neutrophil interaction in patients. Our study demonstrates that CF sol contains substances that can alter the normal functioning of neutrophils and thus may contribute to the bacterial colonization in the CF airway. Further studies will be performed to further identify the precise factors responsible for this observation and isolation of the attenuating factors potentially could serve as therapeutic targets.

\section{ACKNOWLEDGEMENT}

The author thanks Dr. Robert M. Smith UCSD School of Medicine for providing support for this study.

\section{REFERENCES}

[1] Ahuja A, Oh N, Chao W, Spragg R, Smith RM. Inhibition of human neutrophil respiratory burst by native and synthetic surfactant. Am J Respir Cell Mol Biol 1996; 14 (5): 496-503. 
[2] Wlodarczyk R, Sobolewski M, Wojtas G. Role of Oxygen free radicals in the pathogenesis of lung disease. Pol Merkuriuszlek 1999; 6(31): 41-3.

[3] Lawrence RH, Sorrell TC. Decreased polymorphonuclear leucocyte chemotactic response to LTB4 in cystic fibrosis. Clin Exp Immunol 1992; 89: 321-4.

[4] Noah TL, Black HR, Cheng PW, et al. Nasal and BAL fluid cytokines in early CF. J Infect Dis 1997; 175(3): 638-47.

[5] Markert M, Andrews PC, Babior BM. Measurement of superoxide production by human neutrophils and other phagocytic cells. Methods Enzymol 1990; 186: 567-74.

[6] Mayo L, Curnutte J. Kinetic Microplate assy for superoxide production by neutrophils and other phagocytic cells. Methods Enzymol 1990; 186: 567- 75 .

[7] Hulsmann AR, Raatgeep HR, den Hollander JC, et al. Oxidative epithelialdamage produces hyperresponsiveness of peripheral airways. Am J Respir Crit Care 1994; 149: 519-25.

[8] Roberts Rl, Stiehm ER. Increased phagocytic cell chemiluminescence in patients with cystic fibrosis. AJDC 1989; 143: 944-50.

[9] Graft DF, Mischler E, Farell PM, et al. Granulocyte chemiluminescence in adolescent patients with cystic fibrosis. ARRD 1982; 125: 540-4.

[10] Kemp T, Doumont A, Van Geffel R, et al. Alteration of NFMLP induced response in cystic fibrosis neutrophils. Ped Res 1986; 20: 520-6.

[11] Kharazmi A, Schiotz P, Hoiby N, et al. Demonstration of neutrophil chemotactic activity in sputum of CF patients with Pseudomonas. Eur JCI 1986; 16: 143-8.

[12] Kharazami A, Schiotz P, Jensen T, et al. Priming of neutrophils for enhanced oxidative burst by sputum from CF patients with Pseudomonas infection. Eur JC 1987; 17: 256-61.
[13] Collins FS. Cystic fibrosis: molecular biology and therapeutic implications. Science 1992; 256(5058): 774-9.

[14] Yoshimura K, Nakamura M, Trapnell BC, et al. Expression of CFTR gene in cells of non-epithelial origin. Nucleic Acids Res 1991; 19(9): 5417-23.

[15] Dosanjh A, Lencer W, Brown D, et al. Heterologous expression of mutant CFTR in C127 cells results in altered sialylation. Am J Physiol 1994; 266: C360-6.

[16] Gusev GP, Bogdanova AY. Evidence for stimulation of the K-Cl cotransport system by phenazine methosulfate. Biochem Pharmacol 1992; 43(10): 2275-9.

[17] Shen BQ, Barthelson RA, Skach W, et al. Mechanism of inhibition of cAMP-dependent epithelial chloride secretion by phorbol esters. J Biol Chem 1993; 268(25): 19070-5.

[18] Ward PA. Host defense mechanisms responsible for lung injury. J Allergy Clin Immunol 1986 78: 373-8.

[19] Dominguez, Gartner S, Linan S, Cobos N, Moreno A. Enhanced oxidative damage in cystic fibrosis patients. Biofactors 1998; 8(12): $149-53$.

[20] Fick RB, Baltimore RS, Squier SU, Reynolds HY. IgG proteolytic activity of Pseudomonas aeruginosa in cystic fibrosis. J Infect Dis 1998; 151: 589-98.

[21] Suter S, Schaad UB, Roux L, et al. Granulocyte neutral proteases and Pseudomonas elastase as possible causes of airway damage in patients with cystic fibrosis. J Infect Dis 1984; 149: 523-31.

[22] McElvaney NG, Hubbard RC, Birrer P, et al. Aerosal $\alpha-1$ antitrypsin treatment for cystic fibrosis. Lancet 1991; 337: 392-4.

[23] Brockbank S, Downey D, Elborn JS, Ennis M. Effect of cystic fibrosis exacerbation on neutrophil function. Int Immunpharmacol 2005; 5: 601-8.

(C) Amrita Dosanjh; Licensee Bentham Open.

This is an open access article licensed under the terms of the Creative Commons Attribution Non-Commercial License (http://creativecommons.org/licenses/by$\mathrm{nc} / 3.0 /$ ) which permits unrestricted, non-commercial use, distribution and reproduction in any medium, provided the work is properly cited. 